RASĀYAN J. Chem.

Vol. 13 | No. 4 |2523-2529| October - December | 2020 ISSN: 0974-1496 | e-ISSN: 0976-0083 | CODEN: RJCABP

RJC http://www.rasayanjournal.com http://www.rasayanjournal.co.in

\title{
SOLID-PHASE EXTRACTION OF AMOXICILLIN IN AQUEOUS SYSTEM BY USING Mg-AI-OXALATE LDH AS A STATIONARY PHASE
}

\author{
Dian W. Dwiasi ${ }^{1,2}$, Mudasir Mudasir ${ }^{1}$ and Roto Roto ${ }^{1, *}$ \\ ${ }^{1}$ Department of Chemistry, Faculty of Mathematics and Natural Sciences, Universitas Gadjah \\ Mada, Yogyakarta, 55281, Indonesia \\ ${ }^{2}$ Department of Chemistry, Faculty of Mathematics and Natural Sciences, Universitas Jenderal \\ Soedirman, Purwokerto, 53123, Indonesia \\ *E-mail: roto05@ugm.ac.id
}

\begin{abstract}
In this study, a coprecipitation method followed by a hydrothermal treatment was used to synthesize $\mathrm{Mg}-\mathrm{Al}-\mathrm{Ox}$ (Ox $=$ oxalate) layered double hydroxide (LDH), then used as the stationary phase in solid-phase extraction (SPE) for preconcentration of amoxicillin. Extraction was carried out at $\mathrm{pH}$ 7, flow rate $2 \mathrm{~mL} / \mathrm{minute}$, and LDH loading $20 \mathrm{mg}$. The mobile phase is $0.1 \mathrm{M} \mathrm{NaOH}$ solution. The extraction process is still running well for up to three cycles. $\mathrm{LDH}$ Mg-Al-Ox can be a good choice as the SPE stationary phase for the preconcentration of anionic drugs in the environment.
\end{abstract}

Keywords: Solid-phase Extraction, LDH, Amoxicillin, Adsorption, Ion Exchange

(C) RASĀYAN. All rights reserved

\section{INTRODUCTION}

Amoxicillin is one of the extensively administered drugs to treat various infectious diseases ${ }^{1,2}$. There is evidence that a trace of amoxicillin is found in the environment. It could pollute the body of water due to its stable structure, consumption rate, solubility, pharmacological characteristics, and toxicity. It is usually discharged into the environment through the hospital, household, and pharmaceutical industries' waste. The impact of amoxicillin accumulation in the environment could disrupt natural bacterial ecosystems and cause an imminent threat to human health, too. Therefore, the low-level analysis of amoxicillin in the environment remains challenging and urgent. ${ }^{3}$ Monitoring the drug content in the environment is highly required.

Recently, the solid phase extraction (SPE) technique became a very popular method for the enrichment of analytes before their analyses. The SPE is an important technique for the preconcentration of low concentration of drugs in the environment for speed, simplicity, low cost, reusability, low consumption of organic solvent, high recovery, and environmentally friendly. ${ }^{4-6}$ In SPE, the choice of stationary phase will determine the enrichment factor and recovery. Recently, materials such as layered double hydroxide (LDH) have been used as stationary phases for SPE. LDH has been intensively investigated by many researchers for its unique structure and potential applications. ${ }^{7,8}$

The LDH has a memory effect and its interlayer anion is exchangeable by exchange reaction or surface adsorption. ${ }^{9-11}$ Ion exchange is the most common and efficient method used for waste treatment ${ }^{12,13}$. We studied ion exchange between benzoate ions and $\mathrm{NO}_{3}{ }^{-}$ions in the $\mathrm{Mg}-\mathrm{Al}-\mathrm{NO}_{3}$ interlayer. It has an anion exchange capacity of about $40 \mathrm{mg} / \mathrm{g} .{ }^{14}$ We have reported that LDH could be used to immobilize the sunscreen compound and to remove hexacyanoferrate(II) ions. ${ }^{15}$

In this study, we report on the preparation of Mg-Al-Ox and use it as a stationary phase in the SPE. The extraction mechanism is based on the exchange of the oxalate ion in the Mg-Al-Ox LDH interlayer space by the drug anion. To the best of our knowledge, there was no known report on the application of Mg-AlOx as a stationary phase in SPE for amoxicillin extraction. Before extraction, the oxalate ion in the LDH interlayer space was exchanged with amoxicillin anion. 
RASĀYAN J. Chem.

Vol. 13 | No. 4 |2523-2529| October - December | 2020

\section{Materials}

\section{EXPERIMENTAL}

All chemicals were analytical-reagent. Pharmaceutical grade amoxicillin trihydrate (the structure is shown in Fig.-1) was supplied by PPOMN BPOM Jakarta, Indonesia. Magnesium nitrate hydrate, aluminum nitrate hydrate, sodium hydroxide, nitric acid, ethanol, and oxalic acid (Merck, Darmstadt, Germany). Deionized distilled water and nitrogen gas (CV. Perkasa, Yogyakarta, Indonesia).

\section{Instrumentation}

The $3 \mathrm{~mL}$ polypropylene cartridge containing $20 \mathrm{mg}$ Mg-Al-Ox LDH with a cotton-plug tip was used for the extraction of the analyte. A pump was used to control the mobile phase flow rate through the column. Shimadzu FT-IR 820 IPC spectrometer was used to record the FTIR spectra after pelleting with $\mathrm{KBr}$. The XRD data were collected on a Phillips X-ray powder diffractometer equipped with $\mathrm{CuK} \alpha$ radiation with a wavelength of $0.154 \mathrm{~nm}$ operated at $40 \mathrm{kV}$ and $30 \mathrm{~mA}$ with a $2 \theta$ range of 3-90 ${ }^{\circ}$. A JEOL JSM-6510 SEMEDS was used to observe the morphology and elemental analysis. A thermal analyzer of NETZSCH STA 449F1 was used to do thermogravimetry analysis (TGA) and differential thermal analysis (DTA). The S1 Analytics Lab $860 \mathrm{pH}$-meter was used to adjust $\mathrm{pH}$.

\section{Preparation of LDH}

A mixture solution containing $5.12 \mathrm{~g}$ of $\mathrm{Mg}\left(\mathrm{NO}_{3}\right)_{2} \cdot 6 \mathrm{H}_{2} \mathrm{O}$ and $3.75 \mathrm{~g}$ of $\mathrm{Al}\left(\mathrm{NO}_{3}\right)_{3} .9 \mathrm{H}_{2} \mathrm{O}$ was prepared with a $100-\mathrm{mL}$ volumetric flask using deionized water. The $\mathrm{Mg}$ to $\mathrm{Al}$ molar ratio was set at 3 . The mixture was vigorously stirred under $\mathrm{N}_{2}$ gas atmosphere for about 30 min before drop-by-drop addition of $0.1 \mathrm{M} \mathrm{NaOH}$ solution to control the $\mathrm{pH}$ to about 10 . The obtained slurry was hydrothermally treated at $120{ }^{\circ} \mathrm{C}$ for about $20 \mathrm{~h}$ in a Teflon ${ }^{\circledR}$ vessel. The suspension was separated by centrifuge at $4500 \mathrm{rpm}$ for $15 \mathrm{~min}$, washed using deionized water, and dried in an oven at $120^{\circ} \mathrm{C}$ for at least $5 \mathrm{~h}$.

$\mathrm{Mg}-\mathrm{Al}-\mathrm{Ox} \mathrm{LDH}$ was prepared by the ion-exchange method. $0.50 \mathrm{~g} \mathrm{Mg}-\mathrm{Al}-\mathrm{NO}_{3}$ was dispersed in $100 \mathrm{~mL}$ deionized water. The mixture was purged with nitrogen gas for $15 \mathrm{~min}$, and $100 \mathrm{~mL}$ of $0.1 \mathrm{M}$ oxalic acid was added. The stirring was extended for $2 \mathrm{~h}$ under the flow of $\mathrm{N}_{2}$ gas. The slurry was treated hydrothermally at $120^{\circ} \mathrm{C}$ for $20 \mathrm{~h}$. The suspension was centrifuged for $15 \mathrm{~min}$ at $4500 \mathrm{rpm}$, filtered, washed with deionized water, and dried in an oven at $120{ }^{\circ} \mathrm{C}$ for $5 \mathrm{~h}$. The final product was characterized using FTIR, XRD, TGA, and SEM.

\section{Column Preparation}

The SPE column was prepared by inserting $20 \mathrm{mg}$ of the Mg-Al-Ox LDH into the $3 \mathrm{~mL}$ polypropylene SPE cartridge. At the column tip, cotton was plugged to hold the solid in the column. The SPE column was eluted with $2.5 \mathrm{~mL}$ of $0.1 \mathrm{M} \mathrm{NaOH}$ solution to flush and clean the stationary phase. Before each extraction step, the column was conditioned by flushing with $5 \mathrm{~mL}$ of deionized water.

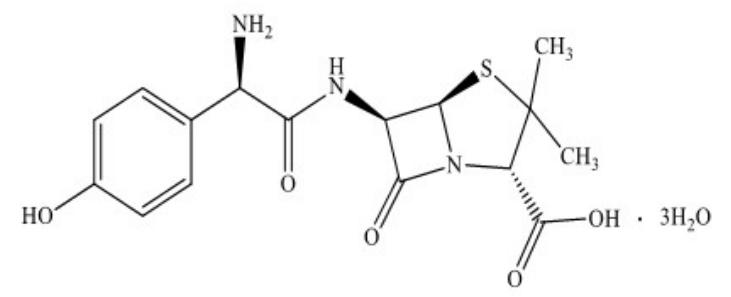

Fig.-1: Chemical Structure of Amoxicillin trihydrate

\section{Extraction Process}

An amoxicillin $80 \mathrm{mg} / \mathrm{L}$ solution measuring $16 \mathrm{~mL}$ was passed through the packed SPE column with a flow rate of $2 \mathrm{~mL} / \mathrm{min}$. After the complete loading of the drug, $2.5 \mathrm{~mL}$ of $1 \mathrm{M} \mathrm{NaOH}$ solution was used to elute the retained drug on the SPE column. The amoxicillin concentration in the eluent was determined by UVVis spectrophotometry at $\lambda 247 \mathrm{~nm}$. The contact time, solution $\mathrm{pH}$, initial amoxicillin concentration, the mass of stationary phase, flow rate, eluent concentration, and volume were first optimized. 
RASĀYAN J. Chem.

Vol. 13 | No. 4 |2523-2529| October - December | 2020

\section{Product Characterization}

\section{RESULTS AND DISCUSSION}

The ion exchange process was done to obtain Mg-Al-Ox LDH. The products were characterized by XRD, FTIR, SEM, and TGA/DTA.

The XRD of the Mg-Al-NO ${ }_{3}, \mathrm{Mg}-\mathrm{Al}-\mathrm{Ox}$, and Mg-Al-Am is displayed in Fig.-2a. The Mg-Al-NO 3 LDH gives $2 \theta$ peaks at $11.34^{\circ}, 23.07^{\circ}$, and $34.55^{\circ}$. They correspond to the $\mathrm{d}_{(003)}, \mathrm{d}_{(006)}$, and $\mathrm{d}_{(009)}$ spacings, respectively. It confirms the previous data for the same LDH with peaks at $2 \theta$ of $11.35^{\circ}, 22.40^{\circ}$, and $34.34^{\circ} .{ }^{16}$ The XRD pattern could be fitted to the hexagonal phase of a typical Mg-Al LDH (JCPDS file 220700). After ion exchange with oxalate, the diffraction peak at $2 \theta 5.33^{\circ}$ is detected. It is consistent with the data in the literature for LDH with oxalate in the interlayer. ${ }^{17}$ The Mg-Al-Am LDH gives diffraction peaks at $2 \theta 8.9^{\circ}$ and $18.1^{\circ}$, which correspond to the $\mathrm{d}_{(006)}$ and $\mathrm{d}_{(009)}$ spacing. However, $\mathrm{d}_{(003)}$ is not detected.

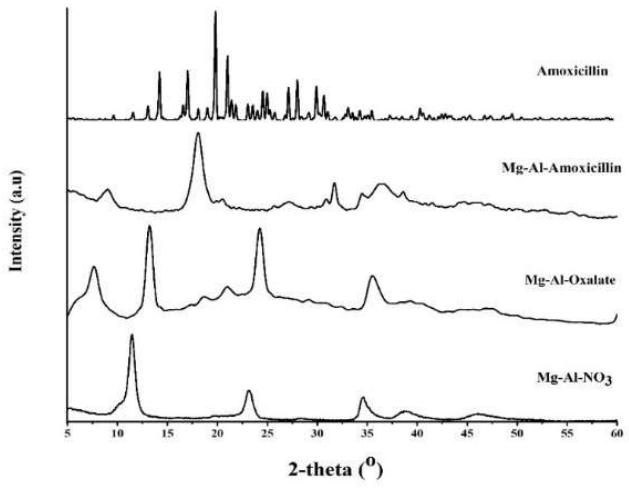

Fig.-2: XRD Pattern before and after Adsorption

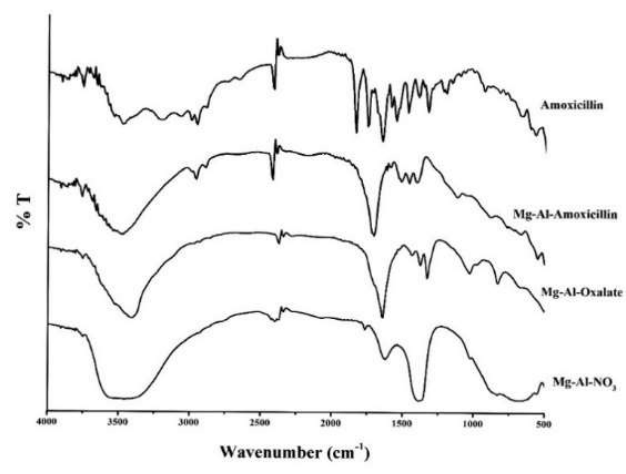

Fig.-3: FTIR Spectra before and after Adsorption

The FTIR spectra of Mg-Al-NO, $\mathrm{Mg}-\mathrm{Al}-\mathrm{Ox}$ before, and after the exchange are shown in Fig.-3. The band at $3400-3500 \mathrm{~cm}^{-1}$ could be assigned as an $\mathrm{O}-\mathrm{H}$ stretching vibration of the LDH octahedral layer and water molecules in the interlayer. For Mg-Al- $\mathrm{NO}_{3} \mathrm{LDH}$, there is a weak band at $1620 \mathrm{~cm}^{-1}$, which could be associated with O-H bending vibrations. A sharp peak that appears at $1381 \mathrm{~cm}^{-1}$ may be attributed to $\mathrm{NO}_{3}{ }^{-}$ asymmetric stretching vibration.

According to the previous study, the LDH FTIR spectra give a band at about $3463 \mathrm{~cm}^{-1}$, which could be ascribed as an $\mathrm{O}-\mathrm{H}$ vibration mode of free water molecules, $\mathrm{M}-\mathrm{OH}$ lattices, and interlayer water molecules. The peak at $1635 \mathrm{~cm}^{-1}$ is the corresponding bending vibration of $\mathrm{O}-\mathrm{H}$. The peak at $1381 \mathrm{~cm}^{-1}$ could be attributed to the asymmetric stretching vibration of nitrate ions. The peaks detected at 617,447 , and 409 $\mathrm{cm}^{-1}$ could be due to the stretching vibration of $\mathrm{M}-\mathrm{O}$. After ion exchange, the $\mathrm{NO}_{3}{ }^{-}$asymmetric vibration is no longer seen. In the Mg-Al-Ox LDH spectrum, the peaks that appear at $1635 \mathrm{~cm}^{-1}$ could be attributed to the $\mathrm{C}=\mathrm{O}$ vibration mode. The peak seen at $1389 \mathrm{~cm}^{-1}$ is due to the $\mathrm{C}-\mathrm{O}$ asymmetric stretching of carboxylate ion. Multiple peaks in the fingerprint region of $400-800 \mathrm{~cm}^{-1}$ are believed to be due to the bending vibrations of the metal oxide of $\mathrm{Mg}-\mathrm{O}, \mathrm{Al}-\mathrm{O}, \mathrm{Mg}-\mathrm{O}-\mathrm{Al}$, and $\mathrm{O}-\mathrm{Mg}-\mathrm{O}$ or O-Al-O. It can be concluded that the oxalate ion has been successfully intercalated into the $\mathrm{Mg}-\mathrm{Al} \mathrm{LDH}$ interlayer gallery.

The peaks at $2924,1774,1690 \mathrm{~cm}^{-1}$ might be assigned as the stretching vibration modes of the $\mathrm{C}_{\mathrm{sp} 3}-\mathrm{H}, \mathrm{C}=\mathrm{O}$, and $\mathrm{C}=\mathrm{C}$ bonds, respectively. The peaks observed at 1582,1481 , and $1090-1020 \mathrm{~cm}^{-1}$ could be assigned as bending vibration modes of the $\mathrm{N}-\mathrm{H}, \mathrm{C}-\mathrm{H}$, and $\mathrm{C}-\mathrm{N}$ bonds. The bending vibration modes of the $\mathrm{C}-\mathrm{H}$ and C-S are viewed at 1000-675 and $563 \mathrm{~cm}^{-1}$, respectively. The peak at $3071 \mathrm{~cm}^{-1}$ is assigned as the stretching vibration mode of the benzene $\mathrm{C}_{\mathrm{sp} 2}-\mathrm{H}$ bond. Also, the peaks at 1597 and $1543 \mathrm{~cm}^{-1}$ could be attributed to the vibration mode of the benzene ring.

Figure-4 shows the TGA traces of Mg-Al- $\mathrm{NO}_{3}$ and $\mathrm{Mg}$-Al-Ox LDH. Mass losses were detected when they were heated from 30 to $600^{\circ} \mathrm{C}$. They are believed to be due to the release of vacuum water, interlayer water, and dehydroxylation. The mass losses are all endothermic as indicated with DTA traces as expected. The mass loss at a temperature below $60{ }^{\circ} \mathrm{C}$ may be due to the loss of vacuum water and the interlayer water is released at $250-370^{\circ} \mathrm{C}$. 
RASĀYAN J. Chem.

Vol. 13 | No. 4 |2523-2529| October - December | 2020

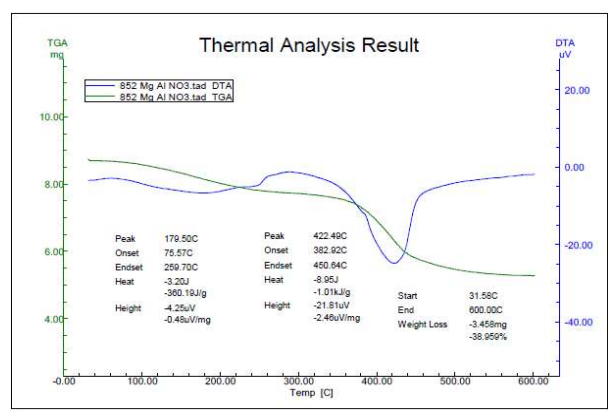

(a)

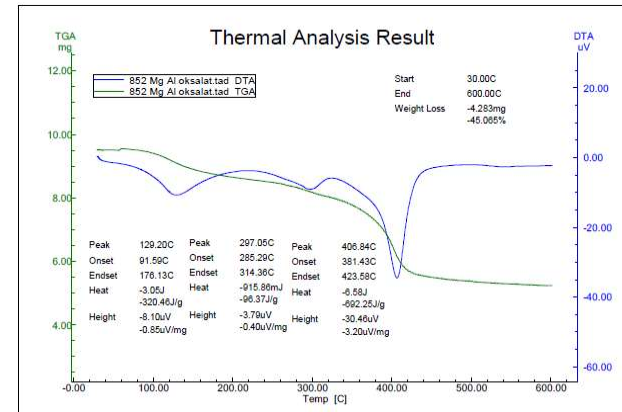

(b)

Fig.-4: TGA and DTA Curves of (a) Mg-Al- $\mathrm{NO}_{3}$, and (b) Mg-Al-Ox

At the onset temperature of $380^{\circ} \mathrm{C}$, the mass loss is believed to be due to the dehydroxylation and removal of the interlayer anions. After dehydroxylation, the remaining compound has $45 \%$ of the initial mass. The final state of the compound after heating at $>500{ }^{\circ} \mathrm{C}$ is ascribed as its corresponding metal oxides. ${ }^{18}$

The SEM images of Mg-Al- $\mathrm{NO}_{3}$ and $\mathrm{Mg}-\mathrm{Al}-\mathrm{Ox} \mathrm{LDH}$ are presented in Fig.-5. It shows that before ion exchange the LDH has a particle size similar to that of after ion exchange. ${ }^{19,20}$

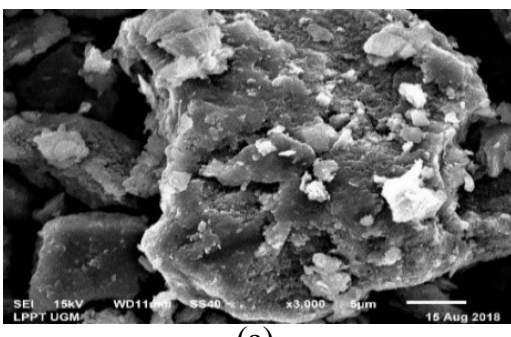

(a)

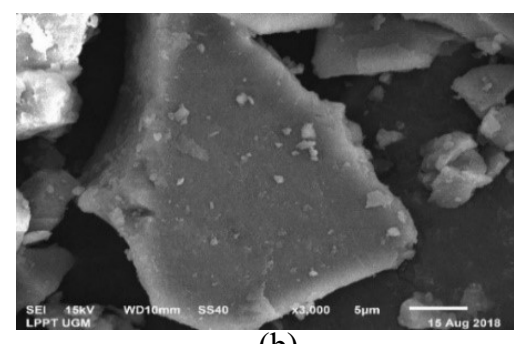

(b)

Fig.-5: SEM Images of (a) Mg-Al- $\mathrm{NO}_{3}$ and (b) $\mathrm{Mg}-\mathrm{Al}-\mathrm{Ox}$

The EDX data are shown in Table-1. The initial Mg to Al molar ratio was 3:1, which is very close to the product of 2.5:1. Note that the $\mathrm{N}$ to $\mathrm{O}$ molar ratio is also comparable with the previous reports. After ion exchange, the atomic molar ratio is reduced slightly.

\section{Solid-phase Extraction Performance}

The amoxicillin immobilization was studied at the $\mathrm{pH}$ range of 4-12. Figure-6a shows the results. The adsorption reaches maxima at $\mathrm{pH}$ 6-8, as suggested in Fig.-6a. At an acidic medium especially at $\mathrm{pH}<6$, the $\mathrm{H}^{+}$concentration is high, which causes the LDH to dissolve partially and gives low adsorption. Whilst at alkaline medium especially at $\mathrm{pH}>8$, the $\mathrm{OH}^{-}$concentration is high. The $\mathrm{OH}^{-}$competes with incoming amoxicillin to replace the oxalate ion and lower the amoxicillin adsorption. ${ }^{21}$ Therefore, a media $\mathrm{pH}$ of 7 was chosen for the extraction.

Table-1: EDS Data of Mg-Al-NO ${ }_{3}$ and Mg-Al-Ox

\begin{tabular}{|c|c|c|c|c|c|c|c|c|c|c|}
\hline \multirow{2}{*}{ Hydrotalcite } & \multicolumn{5}{|c|}{$\%$ Massa } & \multicolumn{5}{|c|}{$\%$ Atom } \\
\hline & $\mathrm{C}$ & $\mathrm{N}$ & $\mathrm{O}$ & $\mathrm{Mg}$ & $\mathrm{Al}$ & $\mathrm{C}$ & $\mathrm{N}$ & $\mathrm{O}$ & $\mathrm{Mg}$ & $\mathrm{Al}$ \\
\hline $\mathrm{Mg}-\mathrm{Al}-\mathrm{NO}_{3}$ & - & 6,28 & 58,15 & 24,47 & 11,09 & - & 8,16 & 66,07 & 18,30 & 7,47 \\
\hline Mg-Al-Ok & 9,46 & 4,35 & 57,83 & 15,10 & 13,26 & 13,52 & 5,34 & 62,05 & 10,66 & 8,44 \\
\hline
\end{tabular}

Figure- $6 \mathrm{~b}$ shows the results of adsorption as a function of time. It appears that the adsorption process occurs rapidly in the first $5 \mathrm{~min}$. It reaches a maximum value after $10 \mathrm{~min}$. The adsorption decreases slightly after $30 \mathrm{~min}$. According to the graph, the best contact time is in the 10-25 min range. In the latter experiments, the contact time was set at $15 \mathrm{~min}$. Figure-6c shows the adsorbed amoxicillin by Mg-Al-Ox LDH at various 
RASĀYAN J. Chem.

Vol. 13 | No. 4 |2523-2529| October - December | 2020

initial concentrations. The adsorption increases rapidly in the initial concentration. It reaches a steady state when the concentration of amoxicillin is set at $100 \mathrm{mg} / \mathrm{L}$. At the initial concentration of $>200 \mathrm{mg}$, no additional amoxicillin is observed.

The effect of the flow rate on the adsorption was studied was investigated in the 1-4 $\mathrm{mL} / \mathrm{min}$ range. Fig.7a shows the data. It suggests that a flow rate of $0.5-2.5 \mathrm{~mL} / \mathrm{min}$ has the highest adsorption. However, at a flow rate of $3 \mathrm{~mL} / \mathrm{min}$ or more, the adsorption begins to decrease. It seems that the extraction is better to be done at the flow rate of about $1-3 \mathrm{~mL} / \mathrm{min}$. In the following experiments, the flow rate was preset at 2 $\mathrm{mL} / \mathrm{min}$.

The amoxicillin adsorption capacity was tested with a variety of stationary phase loading. The data are presented in Fig.-7. In the LDH mass loading of 8-24 mg, it seems that the extraction is not affected by the stationary phase mass loading. Therefore, the LDH mass loading of $20 \mathrm{mg}$ was used in the following experiment.

The type of eluent plays a key role in the SPE. In previous studies, the solutions of $\mathrm{NaOH}, \mathrm{NaCl}, \mathrm{NaF}$, $\mathrm{NaBr}$, and $\mathrm{Na}_{2} \mathrm{CO}_{3}$ were used. The $\mathrm{NaOH}$ solution provides the highest recovery of around $98 \% .{ }^{19}$ In this study, the $\mathrm{NaOH}$ solution was used as an eluent. The concentration of $\mathrm{NaOH}$ solution was investigated in the range of 0.1-2.0 M. It was found that the concentration of $1.0 \mathrm{M} \mathrm{NaOH}$ was suitable for the amoxicillin elution process.

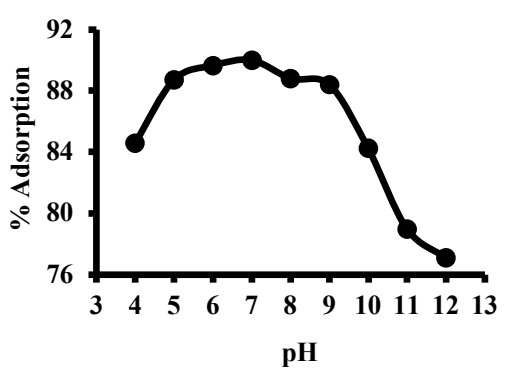

(a)

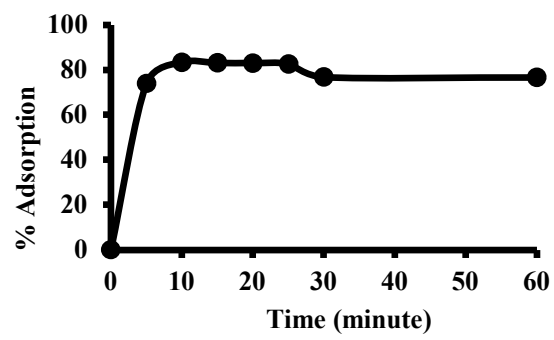

(b)

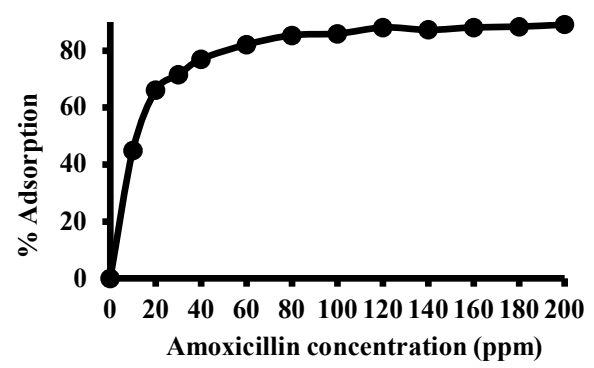

(c)

Fig.-6: Effect of $\mathrm{pH}$ (a), Contact Time (b), and Concentration (c) On the Adsorption Amoxicillin by the Mg-Al-Ox LDH

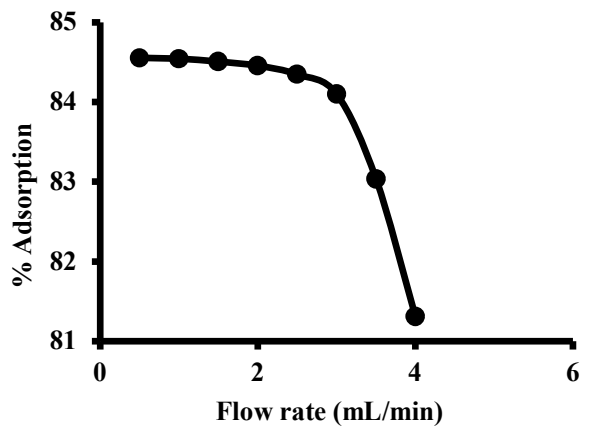

(a)

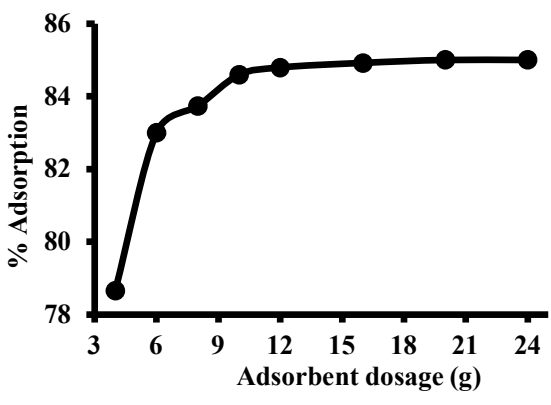

(b) 
RASĀYAN J. Chem.

Vol. 13 | No. 4 |2523-2529| October - December | 2020

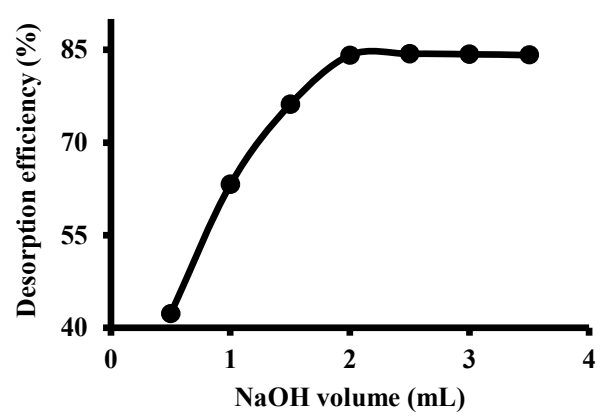

(c)

Fig.-7: Effect of Flow Rate (a), Adsorbent Dosage (b), NaOH Volume (Eluent) (c) on the Adsorption Amoxicillin by the Mg-Al-Ox LDH

Another important factor in the elution process is the eluent volume. The eluent volume determines the enrichment factor. The effect of the eluent volume was studied in the range of $0.5-3.5 \mathrm{~mL}$. As shown in Fig.-7c, there was no significant change in the elution in the range of $1.5-3.5 \mathrm{~mL}$. The volume of the eluent is $2.5 \mathrm{~mL}$.

The recycle test of $\mathrm{Mg}-\mathrm{Al}-\mathrm{Ox} \mathrm{LDH}$ as a stationary phase in SPE is presented in Fig.-8. In the first cycle, it shows a capacity of $21 \mathrm{mg} / \mathrm{g}(84 \%)$ and for the second and third cycles, the extracted compound decreases slightly. It seems that the adsorbed compound. Also, it is likely due to amoxicillin ions which are not completely separated from the active site of the adsorbent. However, the decrease in adsorption capacity in the second and third cycles is not too high, so it can be concluded that the LDH adsorbent Mg-Al-Ox is stable enough to be used up to the third cycle.

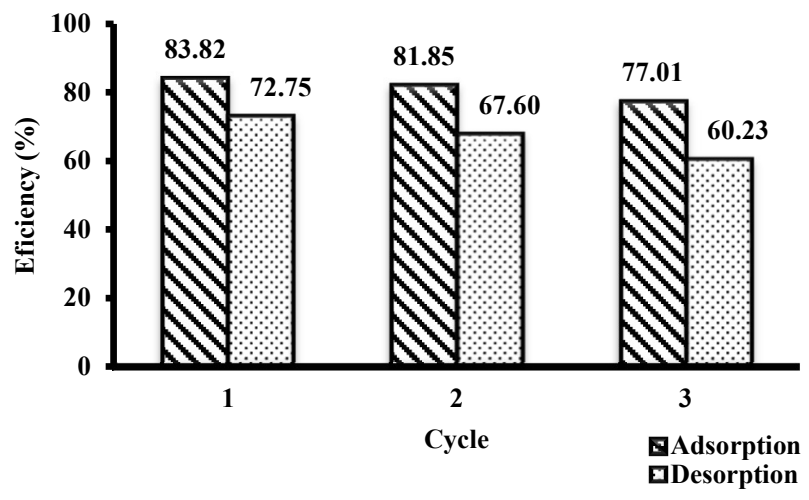

Fig.-8: Reusability

\section{CONCLUSION}

The Mg-Al-Ox LDH was successfully prepared and applied as an SPE stationary phase for amoxicillin extraction. The data suggest that Mg-Al-Ox LDH shows good performance as a stationary phase for the amoxicillin extraction. In general, the LDH may find extensive application in the SPE since it can be synthesized with a variety of cations and charge balancing anions.

\section{ACKNOWLEDGMENT}

This research was supported by the Ministry of Finance of the Republic of Indonesia through the Indonesia Endowment Fund for Education (LPDP) scholarships (Grant number PRJ-4907/LPDP.3/2016).

\section{REFERENCES}

1. C. Chen, J. Li, P. Chen, R. Ding, P. Zhang, X. Li, Environmental Pollution, 193, 94(2014), DOI: 10.1016/j.envpol.2014.06.005 0269-7491 
RASĀYAN $J$. Chem.

Vol. 13 | No. 4 |2523-2529| October - December | 2020

2. A. C. Johnson, V. Keller, E. Dumont, J. P. Sumpter, Science of The Total Environment, 511, 747(2015), DOI:10.1016/j.scitotenv.2014.12.055 0048-9697

3. M. A. Baghapour, M. R. Shirdarreh, M. Faramarziah, Journal of Health Sciences \& Surveillance System, 2, 15(2014)

4. A. A. Gouda, W. A. Zordok, Turkish Journal of Chemistry, 42,1018(2018), DOI:10.3906/kim-17119

5. P. Cai, H. Zheng, C. Wang, H. Ma, J. Hu, Y. Pu, P. Liang, Journal Hazardous of Materials, 213, 100(2012), DOI: 10.1016/j.jhazmat.2012.01.069

6. T. Xue, Y. Gao, Z. Zhang, A. Umar, X. Yan, X. Zhang, Z. Guo, Q. Wang, Journal of Alloys and Compounds, 587, 99(2014), DOI:10.1016/j.jallcom.2013.10.158

7. V. Rives, M. del Arco, C. Martín, Applied Clay Science, 88, 239(2014), DOI:10.1016/j.clay.2013.12.002

8. V. Rives, Nova Science Publisher Incorporation, 2011.

9. M. C. Alexandrica, M. Silion, D. Hritcu, M. I. Popa, Environmental Engineering and Management Journal, 14, 2(2015).

10. W. Zhou, C. Wang, Y. Liu, W. Zhang, Z. Chen, Journal of Chromatography A, 1515, 23(2017), DOI: 10.1016/j.chroma.2017.07.047

11. F. Kovanda, Z. Maryšková, P. Kováŕ, Journal of Solid State Chemistry, 184, 3329(2011), DOI:10.1016/j.jssc.2011.10.029

12. R. Drissi, C. Mouats, Rasayan Journal of Chemistry, 11, 1126(2018), DOI: 10.31788/RJC.2018.1132081

13. A. Girija, R. K. Seenivasan, Rasayan Journal of Chemistry, 6, 212(2013).

14. D. W. Dwiasi, M. Mudasir, R. Roto, Open Chemistry, 17, 1043(2019), DOI:10.1515/chem-2019-0122

15. R. Roto, I. Tahir, M. Mustofa, Indonesian Journal of Chemistry, 7, 1(2010), DOI: 10.22146/ijc.21704

16. J. P. Brady, Queensland University of Technology, 2011.

17. J. Zhang, F. Zhang, L. Ren, D. G. Evans, X. Duan, Materials Chemistry and Physics, 85, 207(2004)

18. R. M. A. Q. Jamhour, S. A. Taher, I. A. Albara, M. A. Ghassab, M. A. A. Tareq, M. A. J. Taghreed, Advances in Analytical Chemistry, 6, 17(2016), DOI:10.5923/j.aac.20160601.03

19. H. Abdolmohammad-Zadeh, F. Morshedzadeh, E. Rahimpour, Journal of Pharmaceutical Analysis, 4, 331(2014), DOI: 10.1016/j.jpha.2014.04.003

20. C. Yang, L. Liao, G. Lv, L. Wua, L. Mei, Z. Li. Journal of Colloid and Interface Science, 479, 115(2016), DOI:10.1016/j.jcis.2016.06.057

21. H. Abdolmohammad-Zadeh, Z. Rezvani, G. H. Sadeghi, E. Zorufi, Analytical Chimica Acta, 685, 212(2011), DOI:10.1016/j.aca.2010.11.035

[RJC-5970/2020] 